\title{
The National Flood-Frequency Program-Methods for Estimating Flood Magnitude and Frequency in Rural Areas on the Island of Tutuila, American Samoa, 2000
}

\section{Introduction}

Estimates of the magnitude and frequency of flood-peak discharges and flood hydrographs are used for a variety of purposes, such as for the design of bridges, culverts, and flood-control structures; and for the management and regulation of flood plains. To provide simple methods of estimating flood-peak discharges, the U.S. Geological Survey (USGS) has developed and published regression equations for every State, the Commonwealth of Puerto Rico, American Samoa, and a number of metropolitan areas in the United States. In 1993, the USGS, in cooperation with the Federal Emergency Management Agency and the Federal Highway Administration, compiled all current USGS statewide and metropolitan area regression equations into a computer program, titled "The National
Flood-Frequency (NFF) Program"

(Jennings and others, 1994).

Since 1993, new or updated regression equations have been developed by the USGS for various areas of the Nation. These new equations have been incorporated into an updated version of the NFF Program.

This Fact Sheet describes the application of the updated NFF Program to streams that drain rural areas on the island of Tutuila, American Samoa. Information on obtaining the NFF software and fact sheets for other areas of the Nation is provided at the end of this Fact Sheet.

\section{Overview}

Wong (1996) developed regression equations for estimating peak discharges
$\left(Q_{T}\right)$, in cubic feet per second, that have recurrence intervals $(T)$ that range from 2 to 100 years for rural, unregulated streams on Tutuila, American Samoa. The equations were developed using ordinary-leastsquares regression techniques. Peak-discharge data from 10 streamflow-gaging stations with 9 to 32 years of record collected between 1958 and 1990 were used in the analyses. The entire island is represented by a single hydrologic region (fig. 1). The equations are not applicable to urban areas.

Recurrence interval is the reciprocal of the annual exceedance probability and represents the average number of years between exceedances. For example, a flood-peak discharge with an exceedance probability of 0.01 has a recurrence interval of 100 years. This does not imply that

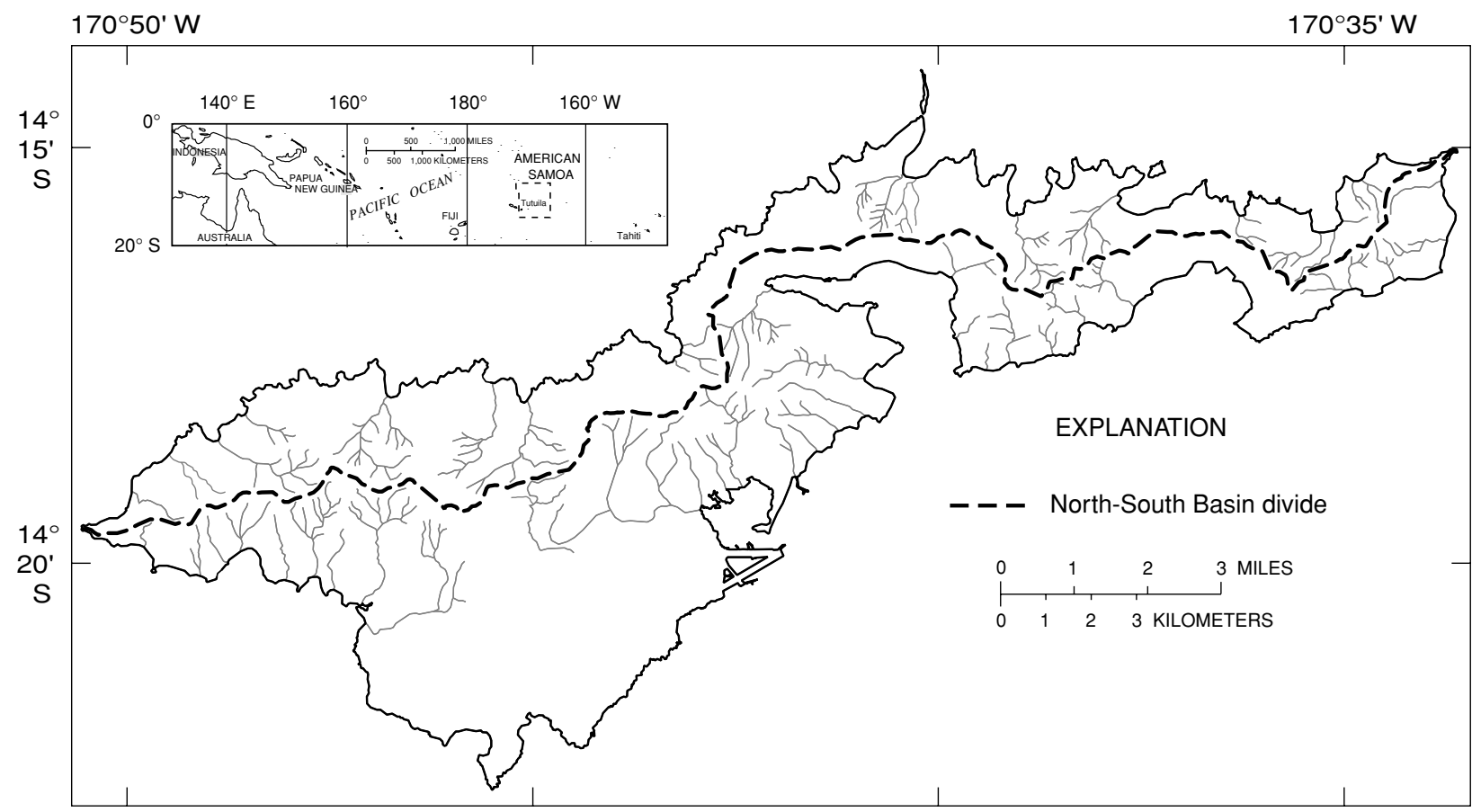

Base modified from U.S. Geological Survey

Tutuila Island, 1:24,000, 1963

Figure 1. The island of Tutuila, American Samoa. 
the 100-year flood will be equaled or exceeded each 100 years, but that it will be equaled or exceeded on the average once every 100 years.

\section{Procedure}

The equations presented by Wong (1996) are shown in table 1. The equations are in the inch-pound system of units; however, the NFF Program will accept and report either the inch-pound or the metric system of units. Drainage area (DA), in square miles, is the only explanatory basin variable that is used in the regression equations for estimating $Q_{T}$ for rural areas. The drainage area is the total area that contributes runoff upstream of the stream site of interest, and is determined from the largest scale topographic map available.

The average standard errors of estimate, and the applicable range of drainage area are shown along with the equations in table 1 . The average standard error of estimate is a measure of the goodness of fit between a regression equation and the data used to derive the equation. Errors in the $Q_{T}$ estimates for about two thirds of the gaging stations used in the regression analysis were within the given standard errors. Errors in the $Q_{T}$ estimates for ungaged sites are somewhat larger than the standard errors of estimate shown in table 1 . The equivalent years of record is the number of years of streamflow record needed to achieve the same accuracy as the equation.

The regression equations are valid only for drainage areas greater than 0.11 and less than 0.78 square miles. Use of the equations for drainage areas near or beyond this range can result in large extrapolation errors. In addition, conditions, such as channelization, urbanization, and diversions, in some drainage basins on Tutuila can be substantially different than those for the gaging stations used in the regression analysis, and users should evaluate whether equation estimates should be used or possibly adjusted in these areas.

\section{Miscellaneous}

Wong (1996) summarized watershed characteristics, peak-discharge estimates, and maximum known discharges for the 10 streamflow-gaging stations used to develop the regression equations. The report also includes regionalized regression equations for mean flow, median flow, and 7-day low flows for 2- and 10year recurrence intervals for ungaged locations. In addition, selected low-flow, flow duration, and daily high-flow characteristics for 11 continuous record stations, 78 low-flow partial record stations, and 49 miscellaneous stream sites are presented.

Table 1. Flood-peak discharge regression equations and associated statistics for streams that drain rural areas of the Island of Tutuila, American Samoa (modified from Wong, 1996)

$\left[Q_{T}\right.$, peak discharge for recurrence interval $T, 2$ to 100 years, in cubic feet per second; $D A$, drainage, in square miles]

\begin{tabular}{|lcc|}
\hline Regression equation & $\begin{array}{c}\text { Average standard } \\
\text { error of estimate, } \\
\text { in percent }\end{array}$ & $\begin{array}{c}\text { Applicable range of } \\
\text { drainage area, } \\
\text { in square miles }\end{array}$ \\
\hline $\mathrm{Q}_{2}=1,040 \mathrm{DA}^{1.13}$ & 47.4 & $0.11-0.78$ \\
$\mathrm{Q}_{5}=1,530 \mathrm{DA}^{1.10}$ & 45.8 & $.11-.78$ \\
$\mathrm{Q}_{10}=1,810 \mathrm{DA}^{1.07}$ & 45.1 & $.11-.78$ \\
$\mathrm{Q}_{25}=2,110 \mathrm{DA}^{1.02}$ & 44.4 & $.11-.78$ \\
$\mathrm{Q}_{50}=2,300 \mathrm{DA}^{0.981}$ & 44.0 & $.11-.78$ \\
$\mathrm{Q}_{100}=2,470 \mathrm{DA}^{0.941}$ & 44.1 & $.11-.78$ \\
\hline
\end{tabular}

-Prepared by Steve S. Sumioka, and Robert R. Mason, Jr., of the U.S. Geological Survey; and Jeffrey N. King and Wilbert $O$. Thomas, Jr., of Michael Baker, Jr., Inc.

\section{References}

Jennings, M.E., Thomas, W.O., Jr., and Riggs, H.C., comps., 1994, Nationwide summary of U.S. Geological Survey regional regression equations for estimating magnitude and frequency of floods for ungaged sites, 1993: U.S. Geological Survey WaterResources Investigations Report 94-4002, 196 p.

Wong, M.F., 1996, Analysis of streamflow characteristics for streams on the Island of Tutuila, American Samoa: U.S. Geological Survey WaterResources Investigations Report 95-4185, $168 \mathrm{p}$.

\section{For more information contact:}

U.S. Geological Survey Office of Surface Water 415 National Center Reston, Virginia 20192 (703) 648-5301

USGS hydrologic analysis software is available for electronic retrieval through the World Wide Web (WWW) at http://water.usgs.gov/software/ and through anonymous File Transfer Protocol (FTP) from water.usgs.gov (directory: /pub/software). The WWW page and anonymous FTP directory from which the National Flood-Frequency software and user documentation can be retrieved are http://water.usgs.gov/software/nff.html and

/pub/software/surface_water/nff, respectively.

Additional earth science information is available from the USGS through the WWW at http://www.usgs.gov/ or by calling 1-888-ASK-USGS. 